\title{
EFFECT OF MUCOADHESIVE POLYMERS ON THE EFFICACY OF ORAL CIPROFLOXACIN HCI TABLETS
}

\author{
Ghada E.Yassin - Dina A. Osman \\ Department of Pharmaceutics, Faculty of Pharmacy, Al Azhar University, Cairo, Egypt
}

\begin{abstract}
Drugs that have a narrow absorption window in the gastrointestinal tract (GIT) will have poor absorption. For these drugs, extending the residence time of a dosage form at a particular site and controlling the release of drug from the dosage form are useful especially for achieving controlled plasma level of the drug as well as improving bioavailability. The objective of this study was to extend the gastric residence time after oral administration and control the release of ciprofloxacin using mucoadhesive tablets. Direct compression method was employed using mucoadhesive polymers namely Carbopol 934, HPMC K4M, HPMC K15M and Tragacanth to prepare several formulations. Moreover, these formulations were subjected to different evaluation studies including content uniformity, surface $\mathrm{pH}$, hardness, friability, tablet dimension, swelling index, mucoadhesive force measurement and in vitro drug release. The release mechanism of Ciprofloxacin $\mathrm{HCl}$ from the matrix tablets indicated super case-II transport mechanism and followed the Higuchi kinetic model. The studies performed on stability showed that there was no change.
\end{abstract}

Key words: Mucoadhesive tablets, Ciprofloxacin $\mathrm{HCl}$, mucoadhesive polymers

\section{INTRODUCTION}

Oral administration is the most convenient, widely utilized, and preferred route of drug delivery for systemic action. However, when administered orally, many therapeutic agents are subjected to extensive presystemic elimination by gastrointestinal degradation and/or first pass hepatic metabolism (Gupta et al., 1990 and Madsen et al., 1998), with low systemic bioavailability, shorter duration and/or formation of in active or toxic metabolites (Jay et al., 2002 and Jimenez et al., 1993). One of the most feasible approaches for achieving a prolonged and predictable drug delivery profiles in gastro intestinal tract is to control the gastric residence time (GRT) using Gastroretentive Dosage Forms (GRDFs) that offer a new and better option for drug therapy (Desia et al., 2007). Dosage forms that can be retained in stomach are called "Gastroretentive Drug Delivery Systems (GRDDS). Gastroretensive systems can remain in the gastric region for several hours and hence significantly prolong the gastric residence time of drugs. Prolonged gastric retention improves bioavailability, reduces drug waste and improves solubility for drugs that are less soluble in a high $\mathrm{pH}$ environment. It has applications also for local drug delivery to the stomach and proximal small intestines. The controlled gastric retention of solid dosage forms may be achieved by the mechanisms of mucoadhesion, flotation, sedimentation, expansion modified shape systems or by the simultaneous administration of pharmacological agents that delay gastric emptying (Mayavanshi et al., 2008 and Garg et al., 2003).

Ciprofloxacin $\mathrm{HCl}$ is an ideal candidate for Gastroretentive drug delivery technology. It is a broad-spectrum fluoroquinolone antibacterial agent that is predominantly absorbed from the stomach and the proximal part of the small intestine. Oral bioavailability is about $70 \%$ and 
reaches the peak plasma concentration $2.5 \mu \mathrm{g} / \mathrm{ml}$ in 1 to $2 \mathrm{hr}$ after administration of $500 \mathrm{mg}$. Plasma half-life is 3-5 hours which favors the development of muccoadhesive tablets.

The objective of this research work is to obtain better delivery of ciprofloxacin $\mathrm{HCl}$ to the stomach and the proximal parts of the small intestine by increasing the mean residence time (MRT) in the stomach in order to increase bioavailability of the drug with minimum side effects, reduce the dosing frequency and improve patient compliance.

\section{MATERIALS AND METHODS}

\section{Materials}

Ciprofloxacin $\mathrm{HCl}$, Hydroxypropyl methyl cellulose i.e. HPMC K4M, HPMC K15M,Carbopol 934, gum tragacanth and Magnesium Stearate, Talc and Lactose were obtained all as gift sample by Sedico for Pharmaceuticals (6 of October, Giza, Egypt). All other chemicals used were of analytical grade.

\section{Methods}

\section{Formulation of Mucoadhesive Tablets}

Ciprofloxacin, carbopol 934, HPMC K4M, HPMC K15M, tragacanth, talc and lactose were blended homogeneously in a mortar according to the quantities given in table (1). Blended mixture was passed through the 60 Sieve and magnesium stearate $1 \%$ was added and blended.The homogeneously blended mixture was compressed in a single-punch tablet machine (Erweka, type EK:0 Erweka Apparatabeous, Frankfurt, Germany) by direct compression method (Ahuja et al., 1997).

Table (1): Formulation composition of Ciprofloxacin $\mathrm{HCl}$ tablet of F1 to F18

\begin{tabular}{|c|c|c|c|c|c|c|c|}
\hline $\begin{array}{c}\text { Formulation } \\
\text { No.* }\end{array}$ & $\begin{array}{c}\text { HPMC } \\
\text { K4M } \\
(\mathrm{mg})\end{array}$ & $\begin{array}{c}\text { HPMC } \\
\text { K15M } \\
(\mathrm{mg})\end{array}$ & $\begin{array}{c}\text { Carbopol } \\
934 \\
(\mathrm{mg})\end{array}$ & $\begin{array}{c}\text { Tragacanth } \\
(\mathrm{mg})\end{array}$ & $\begin{array}{c}\text { Magnesium } \\
\text { stearate } \\
(\mathrm{mg})\end{array}$ & $\begin{array}{c}\text { Talc } \\
(\mathrm{mg})\end{array}$ & $\begin{array}{c}\text { Lactose } \\
(\mathrm{mg})\end{array}$ \\
\hline F1 & 110 & - & - & - & 4.5 & 4.5 & 81 \\
F2 & 125 & - & - & - & 4.5 & 4.5 & 66 \\
F3 & 140 & - & - & - & 4.5 & 4.5 & 51 \\
F4 & - & 110 & - & - & 4.5 & 4.5 & 81 \\
F5 & - & 125 & - & - & 4.5 & 4.5 & 66 \\
F6 & - & 140 & - & - & 4.5 & 4.5 & 51 \\
F7 & 100 & - & 10 & - & 4.5 & 4.5 & 81 \\
F8 & 105 & - & 15 & - & 4.5 & 4.5 & 71 \\
F9 & 80 & - & 20 & - & 4.5 & 4.5 & 91 \\
F10 & - & 90 & 10 & - & 4.5 & 4.5 & 91 \\
F11 & - & 80 & 20 & - & 4.5 & 4.5 & 91 \\
F12 & - & 70 & 30 & - & 4.5 & 4.5 & 91 \\
F13 & 100 & - & - & 10 & 4.5 & 4.5 & 81 \\
F14 & 105 & - & - & 15 & 4.5 & 4.5 & 71 \\
F15 & 80 & - & - & 20 & 4.5 & 4.5 & 91 \\
F16 & - & 90 & - & 10 & 4.5 & 4.5 & 91 \\
F17 & - & 80 & - & 20 & 4.5 & 4.5 & 91 \\
F18 & - & 70 & - & 30 & 4.5 & 4.5 & 91 \\
\hline
\end{tabular}

*Each formulation contains $250 \mathrm{mg}$ of Ciprofloxacin $\mathrm{HCl}$

$*$ Total weight of tablet $=450 \mathrm{mg}$. 


\section{Evaluation of Mucoadhesive Tablets}

All tablets were evaluated for the following parameters: Hardness, Friability, Weight variation, Thickness and Drug content (Mishra et al., 2003). The results of the all evaluated parameters are shown in table (2).

Table (2): Physical properties of tablets of F1 to F18

\begin{tabular}{|c|l|c|c|c|c|c|}
\hline $\begin{array}{c}\text { Formulation } \\
\text { No.* }\end{array}$ & $\begin{array}{c}\text { Thickness* } \\
(\mathrm{cm})\end{array}$ & $\begin{array}{c}\text { Hardness* } \\
\left.(\mathrm{kglcm})^{2}\right)\end{array}$ & $\begin{array}{c}\text { Weight } \\
\text { variation* } \\
(\mathrm{mg})\end{array}$ & $\begin{array}{c}\% \\
\text { Friability }\end{array}$ & $\begin{array}{c}\text { \% Drug } \\
\text { content }\end{array}$ & $\begin{array}{c}\text { Surface } \\
\text { pH }\end{array}$ \\
\hline F1 & $4.23 \pm 0.001$ & $6.102 \pm 0.201$ & $437 \pm 1.23$ & 0.91 & 98.50 & 6.40 \\
F2 & $4.32 \pm 0.0012$ & $6.26 \pm 0.272$ & $456 \pm 1.62$ & 0.87 & 97.25 & 6.40 \\
F3 & $4.56 \pm 0.0011$ & $6.10 \pm 0.268$ & $450 \pm 1.25$ & 0.82 & 96.37 & 6.40 \\
F4 & $4.16 \pm 0.0015$ & $6.02 \pm 0.197$ & $459 \pm 2.02$ & 0.75 & 99.21 & 6.30 \\
F5 & $4.29 \pm 0.001$ & $5.918 \pm 0.307$ & $465 \pm 1.21$ & 0.90 & 100.21 & 6.70 \\
F6 & $4.38 \pm 0.0006$ & $6.428 \pm 0.281$ & $461 \pm 1.06$ & 0.46 & 97.62 & 6.70 \\
F7 & $4.42 \pm 0.0012$ & $7.053 \pm 0.182$ & $460 \pm 1.07$ & 0.22 & 98.76 & 6.40 \\
F8 & $4.30 \pm 0.0015$ & $7.093 \pm 0.235$ & $471 \pm 1.00$ & 0.45 & 99.71 & 6.30 \\
F9 & $4.42 \pm 0.0007$ & $7.142 \pm 0.262$ & $452 \pm 1.09$ & 0.01 & 100.02 & 6.70 \\
F10 & $4.34 \pm 0.0014$ & $5.904 \pm 0.292$ & $453 \pm 1.03$ & 0.09 & 99.26 & 6.88 \\
F11 & $4.13 \pm 0.0019$ & $5.820 \pm 0.301$ & $460 \pm 1.01$ & 0.87 & 97.58 & 6.88 \\
F12 & $4.22 \pm 0.0017$ & $6.028 \pm 0.216$ & $444 \pm 2.01$ & 0.42 & 99.39 & 6.32 \\
F13 & $4.19 \pm 0.0009$ & $6.693 \pm 0.271$ & $449 \pm 1.97$ & 0.75 & 98.62 & 6.82 \\
F14 & $4.22 \pm 0.0013$ & $6.040 \pm 0.231$ & $451 \pm 1.32$ & 0.67 & 97.71 & 6.27 \\
F15 & $4.36 \pm 0.0014$ & $6.897 \pm 0.219$ & $460 \pm 1.76$ & 0.42 & 97.21 & 6.97 \\
F16 & $4.61 \pm 0.00081$ & $6.510 \pm 0.291$ & $451 \pm 1.21$ & 0.67 & 98.71 & 6.35 \\
F17 & $4.43 \pm 0.0019$ & $6.021 \pm 0.232$ & $467 \pm 1.02$ & 0.52 & 99.25 & 6.42 \\
F18 & $4.59 \pm 0.0017$ & $6.102 \pm 0.251$ & $437 \pm 1.40$ & 0.37 & 99.31 & 6.82 \\
\hline
\end{tabular}

$*(\mathrm{n}=3, \pm$ S.D. $)$

\section{Surface $p H$}

A combined glass electrode was used for determination of surface $p H$. The tablets were kept in contact with $5 \mathrm{ml}$ distilled water $\mathrm{pH} 6.5 \pm 0.5$ for $2 \mathrm{~h}$ in $10 \mathrm{ml}$ beakers. The tablets swell up and $p H$ was noted by bringing the electrode near the surface of the formulation after equilibrating for 1 min (Boltenberg et al., 1991). The results are shown in table(2).

\section{Determination of the swelling index(Water Uptake)}

The percentage swelling of tablets were determined for each formulation batch, one tablet was weighted and placed in a beaker containing $200 \mathrm{ml} 0.1 \mathrm{~N} \mathrm{HCl} \mathrm{(pH} \mathrm{1.2).} \mathrm{After} \mathrm{each} \mathrm{interval}$ the tablet was removed from the beaker and weighed again up to 8 hours.

The percentage swelling of tablets is expressed as percentage water uptake (\%WU) and was calculated using the following formula (Noha Adel Naffee et al., 2004 and Baumgartners et al., 2000). The results are shown in Table (3) and figures (1-a, and 1-b)

The percentage water uptake $(\% \mathrm{WU})=\left(\mathrm{W}_{\mathrm{t}}-\mathrm{W}_{0}\right) \backslash \mathrm{W}_{0} \times 100$

$\mathrm{W}_{\mathrm{t}}=$ Weight of tablet at time $\mathrm{t}$.

$\mathrm{W}_{0}=$ Initial weight of tablet before placing in the beaker. 
Table (3): Percentage swelling of formulations F1 toF18

\begin{tabular}{|c|c|c|c|c|c|c|c|c|c|}
\hline \multirow{2}{*}{$\begin{array}{c}\text { Formulae } \\
\text { No. }\end{array}$} & \multicolumn{9}{|c|}{ Time(hrs) } \\
\cline { 2 - 10 } & 1 & 2 & 3 & 4 & 5 & 6 & 7 & 8 & 10 \\
\hline F1 & 128.5 & 135.1 & 139.2 & 139.8 & 140.4 & 142.8 & 144.6 & 145.4 & 146.2 \\
\hline F2 & 117.3 & 122.4 & 129.4 & 130.4 & 132.9 & 135.1 & 138.2 & 140.7 & 144.4 \\
\hline F3 & 105.8 & 115.7 & 122.7 & 128.5 & 130.5 & 135.6 & 139.1 & 140.7 & 141.2 \\
\hline F4 & 64.8 & 76.2 & 114.8 & 120.4 & 125.3 & 130.1 & 131.1 & 134.4 & 135.7 \\
\hline F5 & 78.9 & 85.1 & 124.5 & 125.3 & 127.8 & 129.4 & 130.2 & 131.2 & 132.9 \\
\hline F6 & 79.8 & 88.4 & 128.2 & 128.4 & 128.9 & 130.2 & 131.5 & 131.9 & 132.1 \\
\hline F7 & 87.3 & 92.4 & 110.4 & 116.4 & 119.7 & 122.5 & 126.1 & 128.4 & 130.5 \\
\hline F8 & 97.5 & 100.1 & 125.4 & 127.5 & 128.4 & 130.5 & 132.7 & 134.5 & 135.1 \\
\hline F9 & 97.8 & 105.6 & 122.4 & 126.4 & 128.1 & 130.5 & 135.4 & 137.2 & 138.4 \\
\hline F10 & 60.8 & 84.5 & 91.4 & 110.7 & 117.4 & 119.7 & 122.7 & 123.4 & 124.5 \\
\hline F11 & 68.5 & 80.9 & 110.4 & 114.8 & 119.7 & 120.6 & 122.1 & 123.4 & 123.8 \\
\hline F12 & 74.5 & 100.5 & 115.4 & 115.9 & 116.4 & 116.9 & 117.4 & 117.8 & 118.5 \\
\hline F13 & 69.5 & 80.7 & 117.2 & 119.6 & 120.4 & 121.5 & 122.8 & 123.8 & 124.9 \\
\hline F14 & 74.3 & 90.4 & 119.4 & 120.5 & 121.5 & 123.4 & 124.8 & 125.1 & 125.4 \\
\hline F15 & 71.9 & 87.1 & 120.4 & 122.4 & 124.7 & 124.9 & 125.9 & 126.1 & 126.4 \\
\hline F16 & 81.4 & 100.8 & 126.3 & 127.4 & 127.9 & 128.4 & 128.6 & 128.7 & 129.1 \\
\hline F17 & 86.1 & 111.0 & 127.7 & 128.4 & 128.8 & 129.1 & 129.4 & 129.7 & 130.4 \\
\hline F18 & 84.1 & 117.5 & 127.2 & 129.4 & 130.4 & 132.5 & 133.4 & 133.8 & 134.1 \\
\hline
\end{tabular}

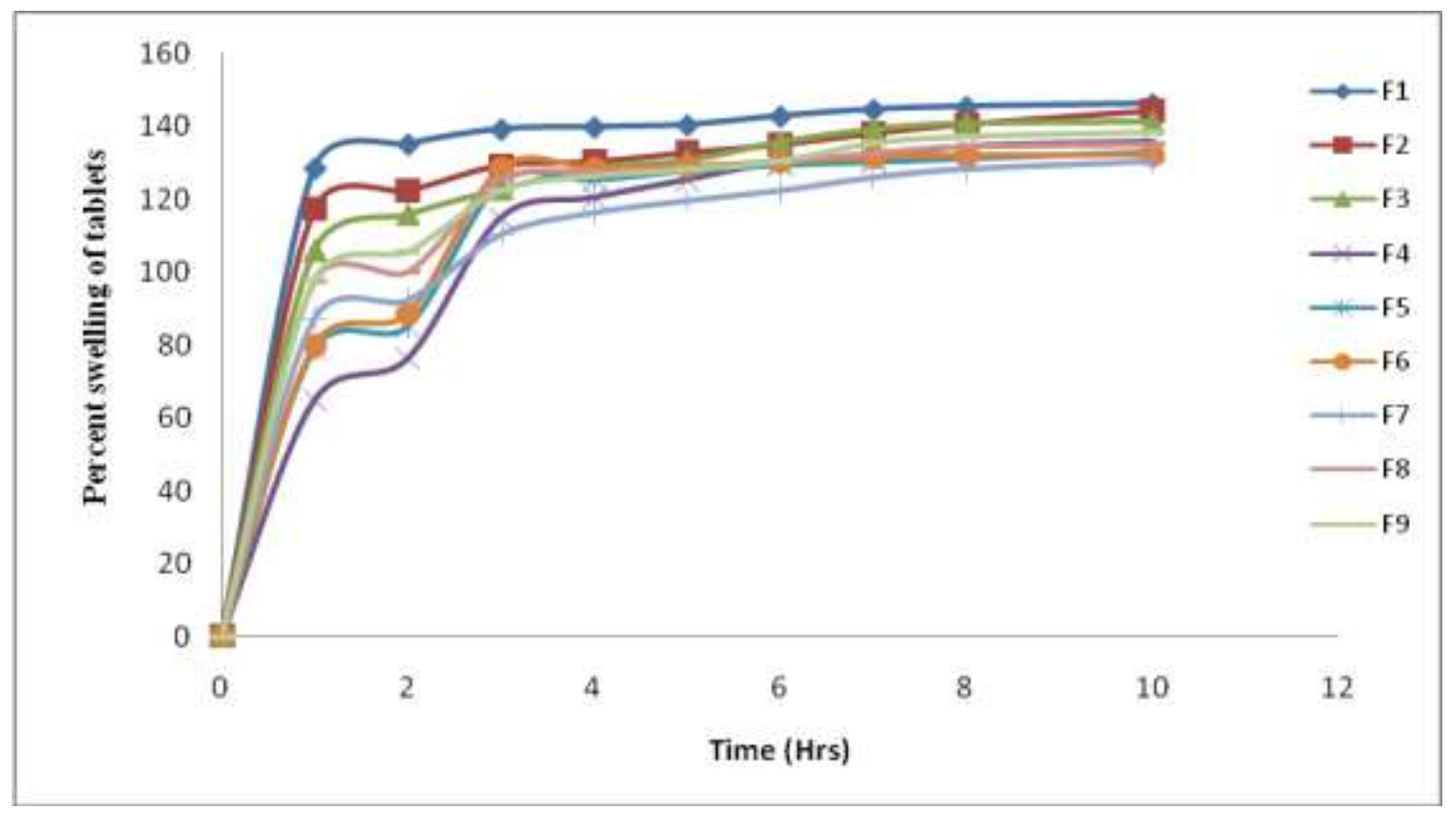

Figure (1-a): Percentage swelling Vs time of formulations F1 to F9 


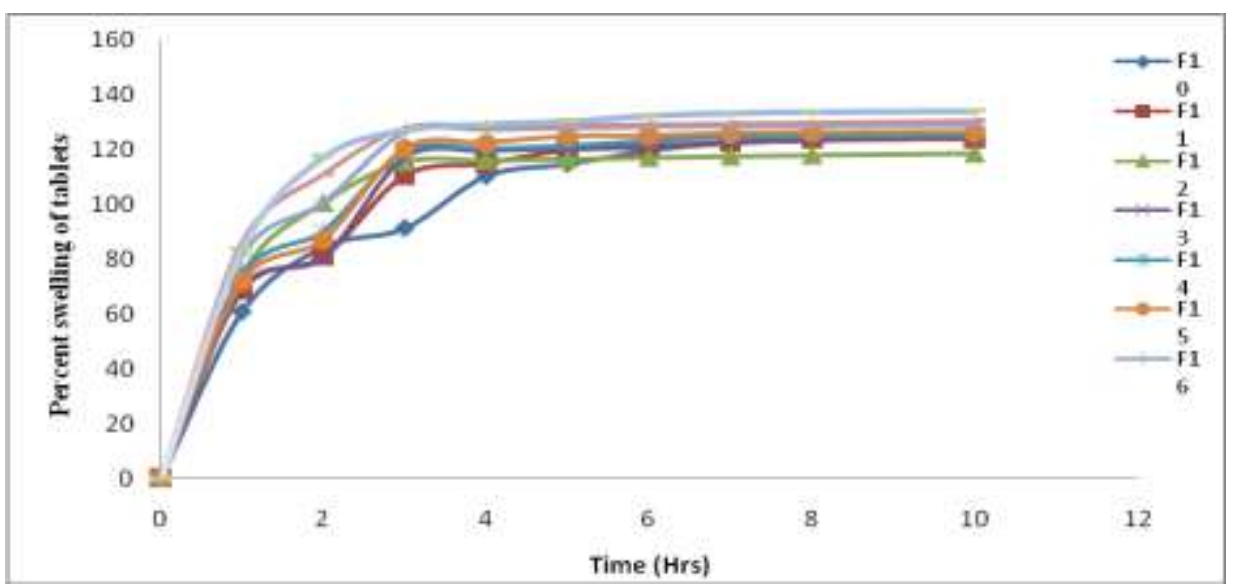

Figure (1-b): Percentage swelling Vs time of formulations F10 to F18

\section{Mucoadhesive strength measurement of tablet}

Mucoadhesive strength of the tablet was measured on 'modified balance method' (Chein, 1992). Briefly, a balance was taken and its left pan was replaced with a weight to the bottom of which a tablet was attached. Both sides were balanced with weight. Porcine gastric mucosa having a thick layer of mucus was fixed to a rubber cork, which was already attached to the bottom of the beaker containing solution of $\mathrm{pH} 1.2$ a moistening fluid with a level slightly above the mucosa. The weight, which was attached to the tablet, was brought into contact with the porcine mucosa, kept undisturbed for 5 minutes and then the pan was raised. Weights were continuously added on the right side pan in small increments and the weight at which the tablet detached from the mucosa was recorded as the mucoadhesive strength. For measuring mucoadhesion time a 10-gram weight was put on right side pan after raising it and the detachment time was noted. The time period throughout which the tablet remained attached to the mucosa is the mucoadhesion time. The obtained results are shown in table (4) and graphically represented by figures (2) and (3).

Force of adhesion $(\mathrm{N})=$ Bioadhesive strength $\times 9.8 \backslash 100$

Table (4): Mucoadhesive strength and force of formulations F1 to F18

\begin{tabular}{|c|c|c|}
\hline Formulation No. & Mucoadhesive Strength (gm) & Mucoadhesive Force (dyne) \\
\hline $\mathrm{F}_{1}$ & $11.23 \pm 1.22$ & 1.10 \\
$\mathrm{~F}_{2}$ & $12.44 \pm 1.09$ & 1.21 \\
$\mathrm{~F}_{3}$ & $17.58 \pm 1.58$ & 1.72 \\
$\mathrm{~F}_{4}$ & $21.59 \pm 1.81$ & 2.11 \\
$\mathrm{~F}_{5}$ & $25.21 \pm 1.56$ & 2.47 \\
$\mathrm{~F}_{6}$ & $33.14 \pm 1.44$ & 3.24 \\
$\mathrm{~F}_{7}$ & $30.87 \pm 2.07$ & 3.02 \\
$\mathrm{~F}_{8}$ & $36.27 \pm 2.11$ & 3.55 \\
$\mathrm{~F}_{9}$ & $38.44 \pm 1.58$ & 3.76 \\
$\mathrm{~F}_{10}$ & $35.04 \pm 1.08$ & 3.43 \\
$\mathrm{~F}_{11}$ & $41.78 \pm 1.27$ & 4.09 \\
$\mathrm{~F}_{12}$ & $46.24 \pm 1.33$ & 4.53 \\
$\mathrm{~F}_{13}$ & $35.44 \pm 1.55$ & 3.47 \\
$\mathrm{~F}_{14}$ & $36.27 \pm 1.81$ & 3.55 \\
$\mathrm{~F}_{15}$ & $36.88 \pm 2.33$ & 3.61 \\
$\mathrm{~F}_{16}$ & $39.77 \pm 2.40$ & 3.89 \\
$\mathrm{~F}_{17}$ & $39.94 \pm 1.90$ & 3.91 \\
$\mathrm{~F}_{18}$ & $40.21 \pm 1.75$ & 3.94 \\
\hline
\end{tabular}




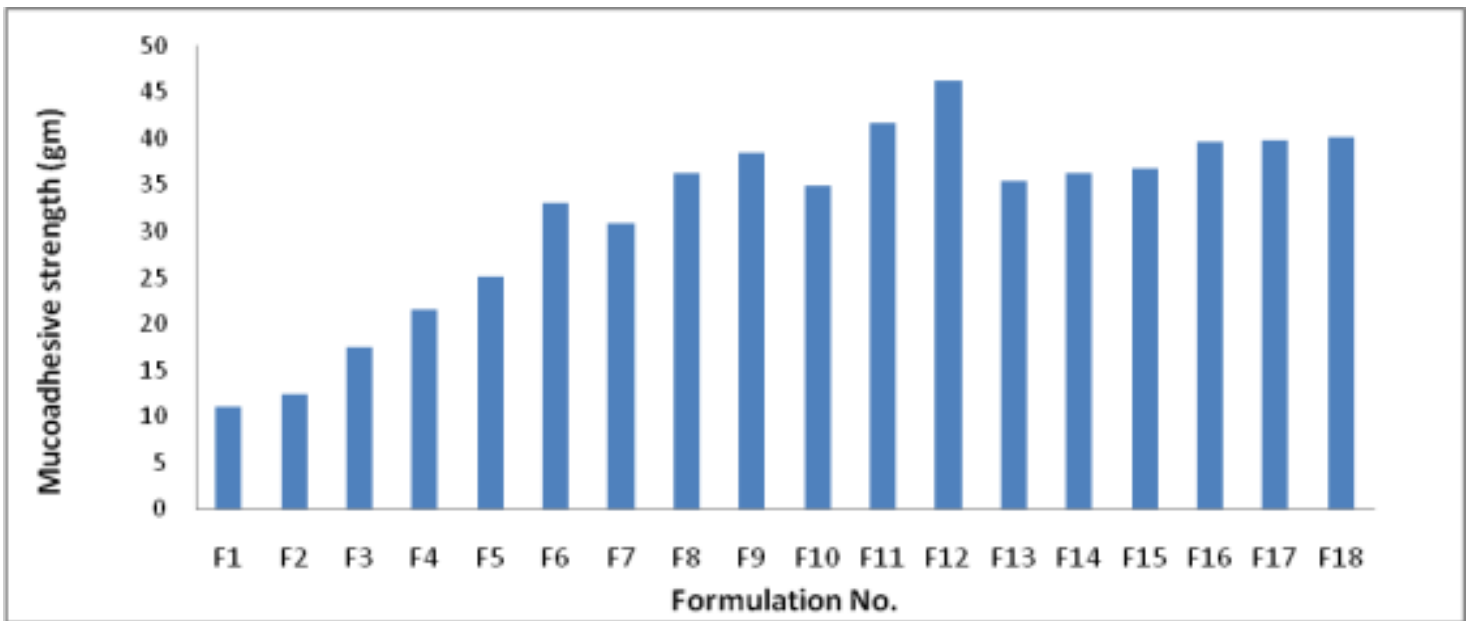

Figure (2): Mucoadhesive strength (gm) of tablets

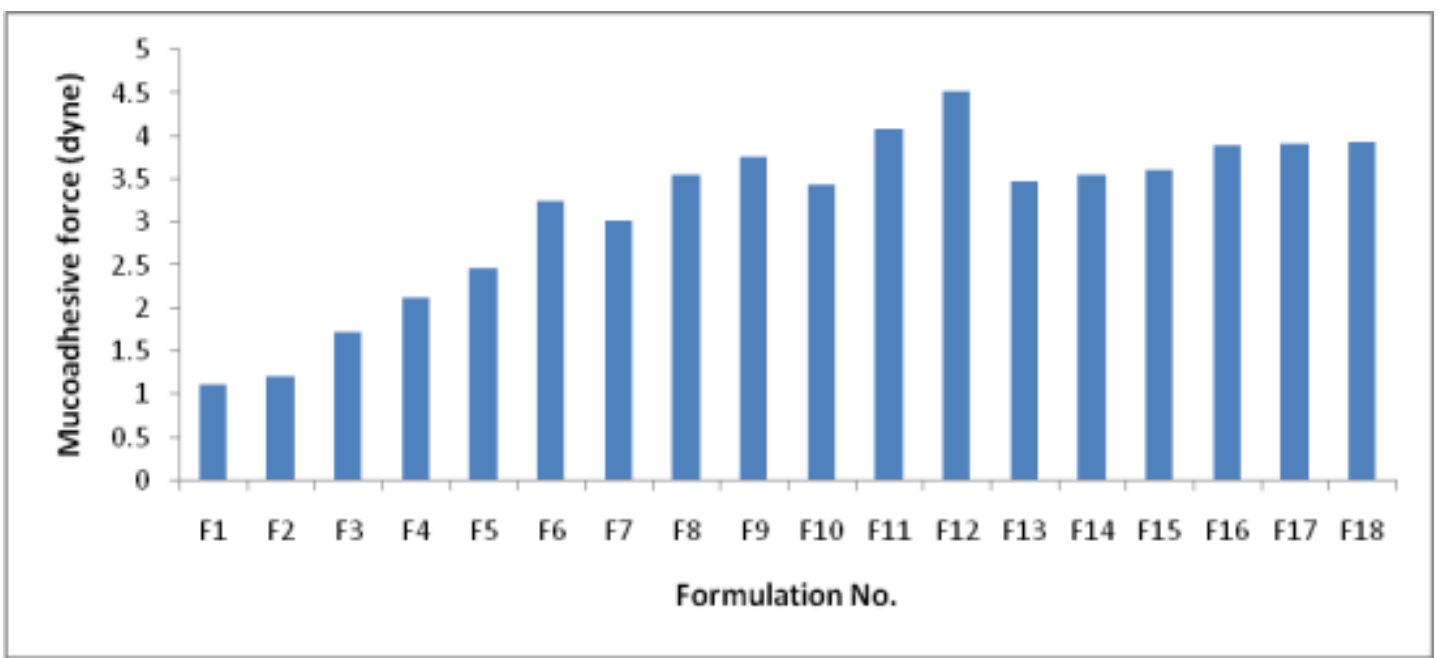

Figure (3): Mucoadhesive force (dyne) of tablets

\section{In vitro drug release study}

The in vitro drug release study was performed using USP dissolution rate test apparatus-II rotated at 50rpm. Dissolution study was carried out for 12 hours in $\mathrm{HCl}(\mathrm{pH} 1.2 ; 900 \mathrm{ml})$ as dissolution medium which is maintained at $37 \pm 0.5^{\circ} \mathrm{C}$.

Samples of each $5 \mathrm{ml}$ were withdrawn for a period of $12 \mathrm{~h}$. Volume in dissolution vessel was kept constant by equal replacement with fresh medium. The samples were collected and filtered through Wattmann filter paper. The amount of the drug in the aliquots was quantified by taking the absorbance of the sample at $276 \mathrm{~nm}$ spectrophotometrically, using $\mathrm{HCl} p H 1.2$ as the blank. Results are shown in table (5), and graphically represented by figures (4) and (5). 
Table (5): Cumulative Drug Release of Formulations F9, F12, F15 and F18

\begin{tabular}{|c|c|c|c|c|}
\hline \multirow{2}{*}{ Time (Hr) } & \multicolumn{4}{|c|}{ Percent Cumulative Drug Release } \\
\cline { 2 - 4 } & F9 & F12 & F15 & F18 \\
\hline 1 & 9.85 & 9.42 & 8.56 & 13.36 \\
2 & 13.16 & 18.36 & 17.21 & 18.07 \\
3 & 21.39 & 23.33 & 20.58 & 23.27 \\
4 & 32.41 & 38.06 & 31.85 & 37.98 \\
5 & 46.21 & 53.85 & 44.48 & 50.27 \\
6 & 60.03 & 75.39 & 60.04 & 74.49 \\
7 & 75.03 & 79.33 & 74.28 & 78.71 \\
8 & 82.97 & 85.68 & 81.55 & 86.28 \\
9 & 91.25 & 89.47 & 90.27 & 89.05 \\
10 & 92.24 & 94.36 & 92.08 & 93.85 \\
12 & 96.55 & 98.21 & 96.21 & 98.05 \\
\hline
\end{tabular}

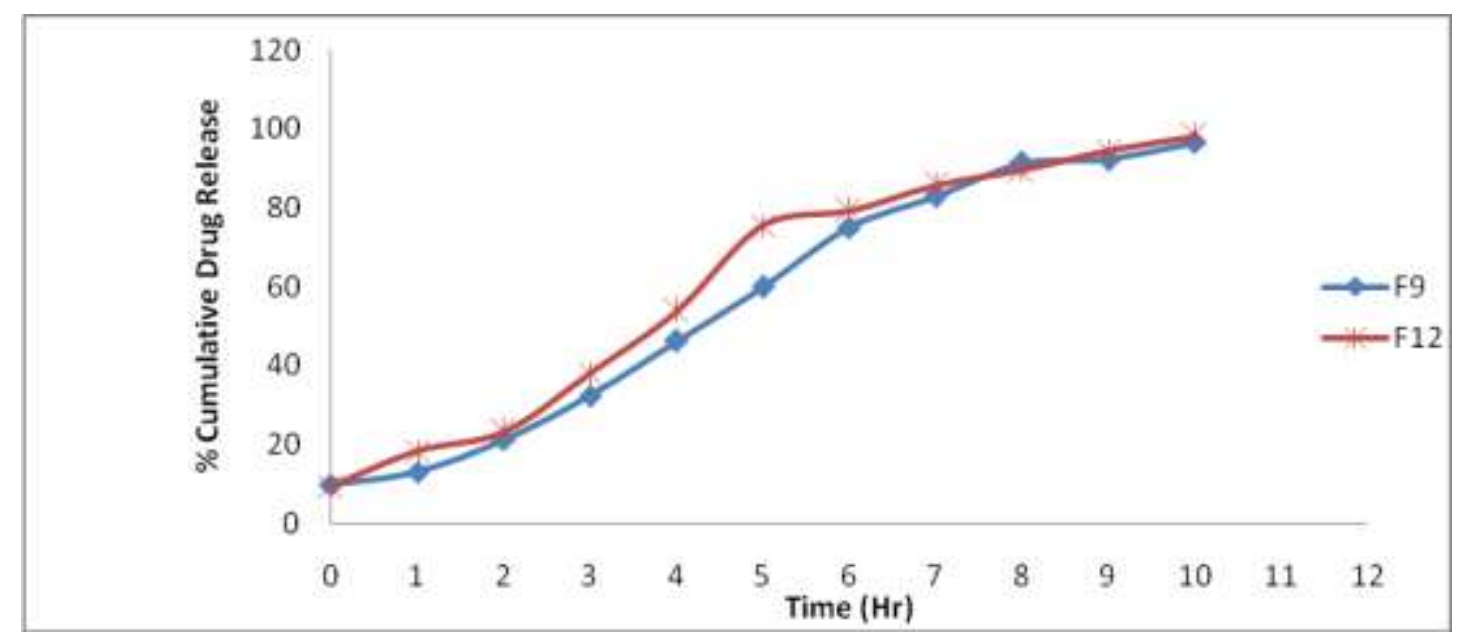

Figure (4): Percent Cumulative Release of Ciprofloxacin HCl Tablets (F9 and F12)

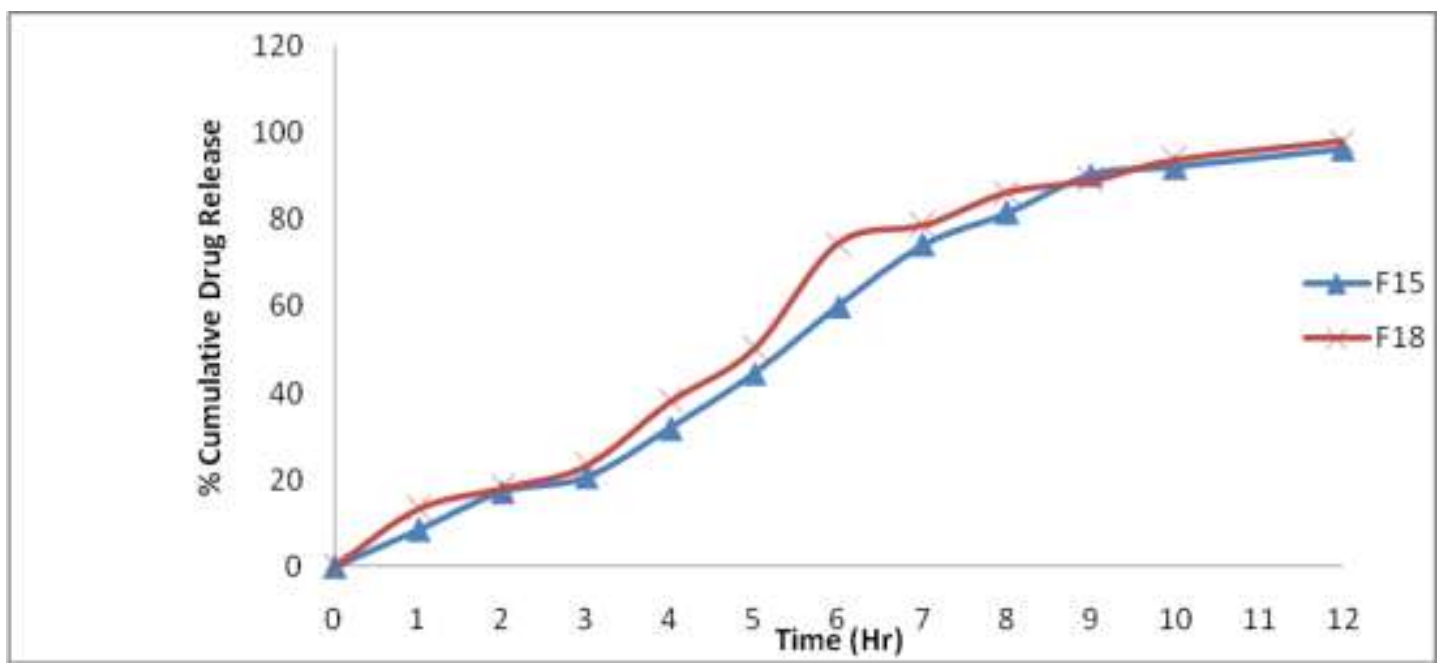

Figure (5): Percent Cumulative Release of Ciprofloxacin HCl Tablets (F15 and F18) 


\section{Kinetic analysis of drug release}

To analyze the mechanism of drug release from the tablets, the in vitro dissolution data were fitted to zero order, first order, Higuchi release model, and Korsmeyer and Peppas model. The model with the higher correlation coefficient $\left(\mathrm{R}^{2}\right)$ was considered to be the best model (Costa, and Lobo, 2001). The data of the release exponent (n) according to Krosmeyer- Peppas is also represented in the table below.

$$
\mathrm{M}_{\mathrm{t}} / \mathrm{M}_{\infty}=\mathrm{kt}^{\mathrm{n}}
$$

Transport Mechanisms from a polymer tablets Under Sink Conditions

\begin{tabular}{|l|l|}
\hline $\mathbf{n}^{\mathbf{a}}$ & Transport Mechanism \\
\hline 0.5 & Fickian diffusion (Higuchi release) \\
\hline $0.5<\mathrm{n}<1.0$ & Non-Fickian (anomalous) \\
\hline 1.0 & Time-independent linear transport (Zero-order release) \\
\hline $\mathrm{n}>1.0$ & Super Case II Transport \\
\hline
\end{tabular}

Results are summarized in table (6).

Table (6): Regression Coefficient $\left(\mathrm{R}^{2}\right)$ Values of Drug Release Data Obtained from Various Kinetic Models and $n$ Value According to Krosmeyer- Peppas

\begin{tabular}{|c|c|c|c|c|c|}
\hline Formulations & Zero order & First order & $\begin{array}{c}\text { Higuchi } \\
\text { model }\end{array}$ & \multicolumn{2}{|c|}{ Korsmeyer \& Peppas } \\
\cline { 2 - 6 } & $\mathrm{R}^{2}$ & $\mathrm{R}^{2}$ & $\mathrm{R}^{2}$ & $\mathrm{R}^{2}$ & $\mathrm{n}$ \\
\hline F9 & 0.9740 & 0.9750 & $\underline{0.9773}$ & 0.9829 & 1.0731 \\
F12 & 0.9609 & 0.9760 & $\underline{0.9771}$ & 0.9851 & 1.0366 \\
F15 & 0.9757 & 0.9750 & $\underline{0.9780}$ & 0.9891 & 1.0699 \\
F18 & 0.9622 & $\underline{0.9743}$ & 0.9729 & 0.9758 & 0.9395 \\
\hline
\end{tabular}

\section{RESULTS AND DISCUSSIONS}

\section{Evaluation of mucoadhesive tablets}

The quality control tests of the prepared mucoadhesive tablets were evaluated. All the batches were produced under the same conditions to avoid processing variables. The \%loss in weight was between 0.01-0.91 percent. The mean thickness of tablets was found to be in the range of $4.13 \mathrm{~cm}$ to $4.61 \mathrm{~cm}$. The percentage weight variation of all formulated tablets passed weight variation test as the \% weight variation was within the standard pharmacopoeia limits (B.P.1993). The hardness of tablets ranged from $5.820-7.142 \mathrm{~kg} / \mathrm{cm} 2$, all parameters are shown in table (2) and they are within the limit. The content uniformity of the drug in the mucoadhesive tablets were within the range from $97.21-100.21 \%$ as shown in table (2). These values are considered acceptable according to USPXXVIIII (2007), which states that, the preparation complies with the test, if the amount of active ingredient in each ten tablets lies within the range of $85 \%$ to $115 \%$ of the label claim. The surface $p H$ studies for different formulations were within the range from 6.30-6.97. The previous parameters are shown in table (2). 


\section{Determination of the swelling index (Water uptake of tablet)}

The results showed that tablets with higher concentration of polymers had lower swellability, this is due to that the more the concentration of the polymer the more the restriction for the polymer movement. Formulations containing HPMCK4M (F1, F2 and F3) had higher percent of water uptake (swelling) than formulations containing HPMC K15M (F4, F5 and F6). This is due to higher crosslinking indicating that polymers having crosslinking constrain and does not facilitate water uptake. The combination between different grades of HPMC, carbopol 934 and tragacanth showed decrease in the water uptake than each polymer alone this revealed to the increase in the crosslinkage of polymers as shown in table (3) and graphically represented by figures (1-a, and 1-b).

\section{Mucoadhesive strength measurement of tablet}

The mucoadhesive strength of the tablets ranged from 11.23 to $46.24 \mathrm{gm}$. and from 1.10 to 4.53 dyne, respectively. A correlation between the percentage of swelling and the mucoadhesive strength has been reported by Fabergas and Garcia, (1995). The initial swelling is due to the hydration, which aids the bioadhesion of tablets, while further increase in swelling induced by over extension of hydrogen bonds and other forces as Van der Waals force and electrostatic forces, these will results in lower bioadhesion as shown in table (4) and graphically represented by figures (2) and (3).

\section{In vitro drug release}

The release of Ciprofloxacin $\mathrm{HCl}$ from the mucoadhesive tablets was studied by plotting cumulative percentage drug release vs. time as shown in table (5) and figures (4) \& (5). The release from the tablets containing hydrophilic polymer should follow three steps, the first step is the penetration of the dissolution medium in tablet (hydration), second step is the swelling with subsequent dissolution or erosion of the tablet and third step is the transport of the dissolved drug to the surrounding dissolution medium (Kiortsis et al., 2005). The release rate was found to be decreased as the concentration of polymer is increased. In the present study the formulations F9, F12, F15 and F18, have shown initial percent drug release after one hour 9.85, 9.42, 8.56 and $13.36 \%$ respectively. After 12 hours the release was found to be 96.55, 98.21, 96.21 and 98.05 for formulationF9, F12, F15 and F18, respectively as shown in table (5) and graphically represented by figures (4) and (5).

\section{Kinetic analysis of drug release}

The drug release from the polymeric system is mostly by diffusion and is best described by Fickian diffusion. But in case of formulations containing swelling polymers, the release is described by other processes in addition to that diffusion would play an important role in exploring the drug release mechanisms. These processes include relaxation of polymer chains, imbibitions of water causing polymers to swell and changing them from initial glassy to rubbery state. Due to swelling, considerable volume expansion take place leading to moving diffusion boundaries complicating the solution of Fick's second law of diffusion (Siepmann and Peppas, 2001). So the release data were further treated by Eq. (4) given by Krosmeyer- Peppas equation. This equation is a generalization of the observation that superposes two apparently independent mechanism of drug transport, Fickian diffusion and a case-II transport describes drug release from a swelling polymer, and the drug transport mechanism associated with stress and state transition in hydrophilic glassy polymers which swells in water or biological fluid (Cox et al., 1999). When $n$ takes the value 0.5 it indicates diffusion-controlled drug release and for the value 
1.0 indicates swelling-controlled drug release. Values of $\mathrm{n}$ between 0.5 and 1.0 can be regarded as an indicator for the both phenomena (anomalous transport). These extreme values for the exponent $\mathrm{n}, 0.5$ and 1.0, are only valid for slab geometry and for spheres and cylinders different values have been derived. For a matrix tablet, a cylindrical geometry is considered and as per Ritger and Peppas $n$ takes values in the range of 0.45-0.89 for anomalous transport (Ritger and Peppas, 1987). The regression coefficient $\left(r^{2}\right)$ values of the released data of the selected formulation for zero, first order and Higuchi model are reported in table (6). Most of the formulations follow Higuchi model which indicates that the drug release depends on time, while formulation F18 follows the first order. The $r^{2}$ value is $0.9773,0.9771,0.9780$, and 0.9743 for F9, F12, F15 and F18 respectively. The mechanism of drug release is predicted by using KrosmeyerPeppas equation. The $\mathrm{n}$ value was found to be 1.073, 1.0366, 1.0699 and 0.9395 for formulation F9, F12, F15 and F18 respectively. The phase transition was shown in figures (4) and (5).

The results of this study revealed that in all cases, irrespective of the type of polymer, $n$ values are between 0.9395 and 1.0731, indicating a non-Fickian release behavior and Super Case II transport.

\section{CONCLUSION}

In the present investigation, Ciprofloxacin $\mathrm{HCl}$ oral mucoadhesive tablets were formulated using various polymers as Hydroxypropyl methylcellulose K15M,Hydroxypropyl methylcellulose K4M,Carpopol 934 and Tragacanth which were used as hydrophilic matrix and mucoadhesive polymer in varying concentrations with Magnesium stearate, Talc and Lactose as fillers. Tablets were subjected to various evaluation parameters such as drug content, hardness, weight variation, friability, thickness, muccoadhesive strength, swelling index, and in vitro drug release study. All tablets show acceptable physical parameters. Formulations F9, F12, F15 and F18 have good muccoadhesive along with good swelling behaviors and in vitro release. The release form the selected formulations were controlled over 12 hours. The studies performed on stability showed that there was no change. It was observed that the studied tablets followed first order and Higuchi model and Peppas release mechanism which seems to be a complex mechanism include swelling, diffusion and erosion.

\section{REFERENCE}

Ahuja A, Khar RK and Ali J., (1997): Mucoadhesive drug delivery systems. Drug Dev. Ind. Pharm., 23(5): 489- 515.

BaumgartnerS. ,KristJ., VodopivecP., ZorkoB. (2000): Optimization of floating matrix tablets and evaluation of their gastric residence time.Int.J.Pharm.195:125-135.

Boltenberg B., (1991): Development and testing of bioadhesive fluoride containing slow release tablets for oral use. J Pharm. Pharmacol.; 43: 457-61.

Chien YW., (1992): Novel drug delivery systems.2nd ed. Marcel Dekker Inc., NY, pp.171-176.

Costa, P., Lobo, J.M.S., (2001): Modeling and comparison of dissolution profiles, Euro.J.Pharm.Sci, , 12, 123-133. 
Cox PJ, Khan KA, Munday DL andSujja-areevath J., (1999): Development and evaluation of a multiple-unit oral sustained release dosage form for $\mathrm{S}(+)$-ibuprofen:preparation and release kinetics.Int.J.Pharm.,193:73-84.

Desia, J.U., Parikh, J.R., Parikh, R.H., (2007): Floating drug delivery systems: An approach to gastro retention, Pharmainfonet, 5(1).

Fabregas, JL and Garcia, N., (1995): In-vitro studies onbuccoadhesive tablet formulation of HydrocortisoneHemisuccinate, Drug Develop Ind. Pharm; Vol.21, No. 9: 1689-1696

Garg, S., Sharma, S.,(2003): Gastroretentive drug delivery systems, Busi.Briefing: Pharmatech, , $160-166$.

Gupta PK, Leung SHS and Robinson JR., (1990): In: Bioadhesive Drug Delivery Systems (Lenaerts V and Gurny R Eds.), CRC Press, Boca Raton, Florida, pp.65 -92.

Jay S, Fountain W, Cui Z and MumperR J., (2002): Transmucosal delivery of testosterone in rabbits using novel bi-layer mucoadhesive wax-film composite disks. J. Pharm. Sci., 91(9): 2016-25.

Jimenez CNR, Zia H and Rhodes CT.,(1993): Mucoadhesive drug delivery system. Drug Dev. Ind. Pharm., 19: 143-94.

Kiotsis S., Kachrimanis K., Broussalia Th. and Malamataris S., (2005): Drug release from tableted wet granulations comprising cellulosic (HPMC or HPC) and hydrophobic component, Eur.J. Pharm. Biopharm., 59:73-83.

Korsmeyer RW Lustig SR and Peppas NA., (1986a): Solute and pentrant diffusion in swellable polymers. I. Mathematical modeling.J. polym.Sci. Polym. Phys. Ed., 24395-408.

Madsen F, Eberth K and Smart JD., (1998): A rheological examination of mucoadhesive/mucus interaction: the effect of mucoadhesive type and concentration. J. Contr. Rel., 50: 167-78.

Mayavanshi, A.V., Gajjar. S.S., (2008): Floating drug delivery systems to increase gastric retention of drugs: A Review, Research J.Pharm.and Tech, 1(4).

Mishra B, Jayanth P and Shankar C., (2003): Development of chitosan -alginate microcapsule for colon specific delivery of metronidazole.indian drugs.,40: 695- 700.

Noha Adel Naffee, Fatma Ahmed Ismail andNabila Ahmed Boraje., (2004): Mucoadhesive delivery systems. II formulation and invitro/ invivoevaluation of Buccal Mucoadhesive tablets containing water soluble drug. Drug Dev. and Ind. Pharmacy, Vol. 30 (9), P 995-1004.

Ritger PL and Peppas NA., (1987): A simple equation for description of solute release II. Fickian and anamalous release from swellable devices. J. Contr. Rel., 5: 37-42.

Siepmann. J., and Peppas. NA., (2001): Modeling of drug release from delivery systems based on hydroxypropyl methylcellulose (HPMC).Adv. Drug Deliv. Rev., 48:139-157.

The United States pharmacopoeia XXVIIII and NF XXV (2007): American pharmaceutical association Washington, DC, Electronic version. 


\section{تأثير المواد العديدة الجزيئات اللاصقه للفشاء المخاطي علي كفاءة \\ عقار السيبرو فلوكساسين أيدروكلوريد المعطاة عن طريق الفم \\ غادة إيهاب يس- دينا علي عثمان}

قسم الصيدلانيات و الصيدلة الصناعيةـ كلية الصيدلة- جامعة الازهر فرع البناتـ مدينة نصر ـ القاهرة

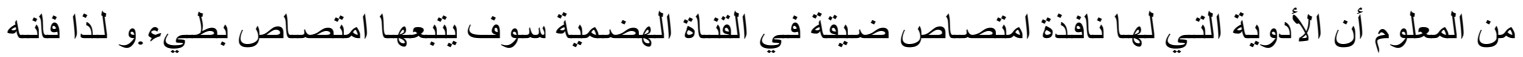

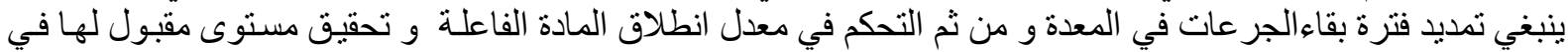

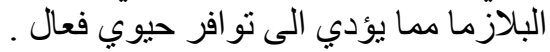

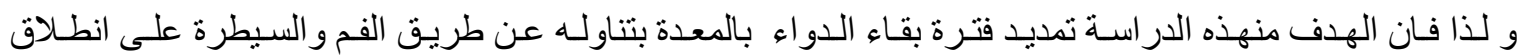

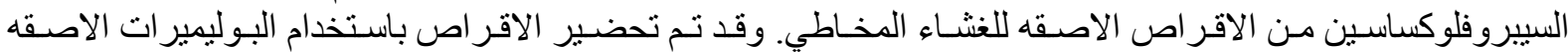

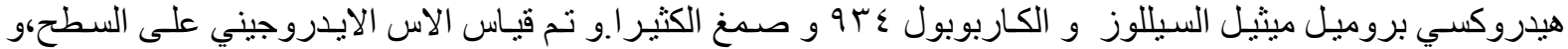
الخو اص الفيزيقيه للاقر اص مع قياس الانطلاق المعملي للعقار .

وقد وجد أن الاقر اص متو افقة من حيث الثكل الخـارجي ،درجـة التماسك، الصـلابة ،الزمن الازم للتفتت و تجانس لإنس محتويات ألاقر اص و ثنبات الاصنها.

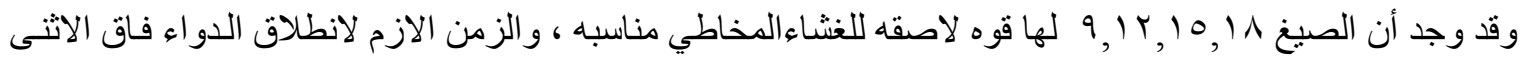

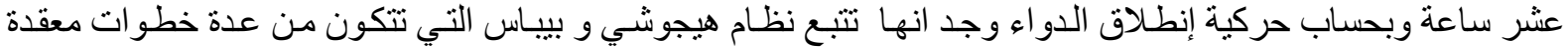
تشمل الانتفاخ و الانتشار و التآكل. 